\title{
«LA INTEGRACIÓN EUROPEA A TRAVÉS DEL DERECHO». LA CONTRIBUCIÓN DEL TRIBUNAL CONSTITUCIONAL FEDERAL $(\text { ALEMÁN })^{1}$
}

\author{
ANDREAS VOSSKUHLE \\ Presidente del Tribunal Constitucional Federal Alemán ${ }^{2}$ \\ Catedrático de Derecho Público Universidad de Friburgo
}

\section{SUMARIO}

I. La idea de una comunidad jurídica europea. II. El impulso juridificador en la jurisprudencia del Tribunal Constitucional Federal (alemán). III. Contracorriente: ¿está sobrecargada la idea de comunidad jurídica?

\section{LA IDEA DE UNA COMUNIDAD JURÍDICA EUROPEA}

La Unión Europea está cuestionada. Setenta años después del final de la Segunda Guerra Mundial, la radiante promesa de libertad, paz, prosperidad y solidaridad con la que el proceso europeo una vez brilló parece haberse perdido. Los principales desafíos, presididos por la crisis de la deuda soberana y financiera, no solo han destapado errores estructurales y cambios de poder a nivel institucional $^{3}$ sino que, también, han puesto de manifiesto el egoísmo de los Estados miembros y, a su vez, han permitido que florezcan dudas relativas a la cohesión interna de la Unión Europea. Estas fuerzas centrífugas se han intensificado, aún más, debido a los retos a los que se enfrenta la Unión Europea como consecuencia de

1 Traducción realizada por Pablo Sánchez-Molina (Personal investigador en formación, programas de becas de la obra social «la Caixa» en la Universidad de Sevilla).

2 Director del Institut für Staatswissenschaft und Rechtsphilosophie (Sec. I) en la Albert-Ludwigs-Universität Freiburg. Este artículo se basa en una ponencia que realicé el 22 de octubre de 2015 como parte de la serie de conferencias «Humboldt Reden zu Europa» celebrada en la Universidad Humboldt de Berlín. Doy las gracias a mi secretario judicial Dr. Friedrich Schütter por su valiosa asistencia.

3 Cf., e.g., más recientemente Rodi, 2015 (737 y ss.). 
la incesante afluencia de refugiados. En este momento de incertidumbre ${ }^{4}$, podría resultar de utilidad poner de relieve los logros conseguidos, hasta la fecha, en el proceso de integración europea.

Probablemente, uno de los grandes éxitos de Europa en las últimas décadas ha sido el desarrollo de una comunidad jurídica efectiva ${ }^{5}$. Hay una razón para ello: la preservación de los valores sobre los que se fundamenta la Unión Europea $^{6}$, así como la consecución de sus objetivos, no puede realizarse en un grupo de 28 Estados miembros con características históricas, culturales, sociales y económicas muy diversas sin que se respeten las normas que la propia Unión Europea se dio a si misma. En este contexto, el Derecho a nivel europeo cumple varias funciones: orienta, ayuda tanto a evitar como a superar conflictos y proporciona legitimidad asignando competencias y estableciendo procedimientos para la toma de decisiones. Precisamente en la Unión Europea, donde las fuerzas de cohesión no son elevadas, principalmente, por los diferentes intereses de los Estados miembros, aparece la capacidad de integración del derecho. Así, incluso en tiempos de crisis, sigue siendo la base más estable de Europa ${ }^{7}$.

Muchos actores están involucrados en la implementación de la idea de comunidad jurídica, tan enfáticamente reclamada por Walter Hallstein ${ }^{8}$. Entre ellos los gobiernos de los Estados miembros, que negocian y desarrollan los tratados, el Parlamento Europeo y el Consejo que, junto con la Comisión, promulga el Derecho derivado; el Tribunal de Justicia de la Unión Europea, que garantiza la observancia de la ley en la interpretación y aplicación de los trata$\operatorname{dos}^{9}$; los parlamentos nacionales, administraciones y tribunales que son responsables de la puesta en práctica del Derecho de la Unión Europea; y, no menos importante, los ciudadanos, que pueden participar en el discurso jurídico de diversas maneras, por ejemplo a través de asociaciones e iniciativas ciudadanas. En sí mismo, el número de actores implicados demuestra que el establecimiento y desarrollo de la comunidad jurídica europea tiene lugar dentro de un proceso extremadamente complejo caracterizado por un alto nivel de interconexión e interdependencia. Este es un proceso en el que las condiciones para el éxito y los peligros solo pueden reflejarse en parte. En este contexto me gustaría examinar más de cerca la contribución, en las últimas décadas, del Tribunal Constitucional Federal Alemán a la «integración [europea] a través de la ley» ${ }^{10}$ y considerando diez impulsos centrales de la legitimación (II.).

4 Con consecuencias radicales, ver por ejemplo Streeck, 2015.

5 Expresamente, Volkmann, 2014 (1061 y ss.). En detalle Voßkuble, 2015, (135 y ss.).

6 Con mayor detalle Calliess, 2004 (1033 y ss.); Sommermann, 2014 (287 y ss.) que contiene referencias adicionales.

7 Con dudas, por ejemplo P. Kirchbof, 2012; id., 2013, (3); Graf Kielmannsegg, 2012; Schmidt, 2013 (para. 60): «La crisis financiera actual ha sido causada por no respetar la ley»; id., 2012; Huber, 2015.

8 Hallstein, 1962 (341 y ss.).

9 En lo referente a las tareas del TJUE en la crisis, cf. especificamente Everling, 2015 (85 y ss.).

10 Término acuñado en Cappelletti/Seccombe/Weiler, 1986. 
Algunas reflexiones sobre posibles límites a la idea de la comunidad jurídica (III.) completarán estas reflexiones.

\section{EL IMPULSO JURIDIFICADOR EN LA JURISPRUDENCIA DEL TRIBUNAL CONSTITUCIONAL FEDERAL (ALEMÁN)}

\section{Apertura de la Constitución a la integración, y orientación jurídica del proceso de integración}

Comencemos con un ejemplo célebre de juridificación: la inserción del artículo 23, conocido como la «cláusula Europa», en la Ley Fundamental de 1992. Durante la nueva redacción de este artículo, el poder legislativo, encargado de la reforma de la Constitución, siguió muy de cerca los principios clave dados por el Tribunal Constitucional Federal sobre de la integración europea.

En 1967, el Tribunal Constitucional Federal declaró que la entonces Comunidad Económica Europea gozaba de un carácter especial al estar inmersa en un proceso de integración permanente en el que la República Federal podía transferir derechos soberanos sobre la base del art. 24 de la Ley Fundamental ${ }^{11}$. Así, en una fase muy temprana, el Tribunal enfatizó la apertura de la Ley Fundamental a la integración europea. Sus declaraciones sirvieron de modelo para fijar como objetivo nacional fundamental el establecimiento de una Europa unida siguiendo el mandato constitucional del art. 23.1 (primera frase) y reforzado a través del compromiso recogido en el preámbulo de la Ley Fundamental.

Al mismo tiempo, en la sentencia Solange I, de 1974, el Tribunal Constitucional Federal desarrolló una guía legal para el proceso interno de integración, condicionando la admisibilidad de la transferencia de derechos soberanos al cumplimiento de ciertos requisitos estructurales ${ }^{12}$ : la protección de la identidad constitucional nacional, la protección de los Derechos Fundamentales y la asignación de competencias. En este sentido, el Tribunal sostuvo que los Derechos Fundamentales recogidos en la Ley Fundamental formaban parte de los «rasgos esenciales» de la propia Ley Fundamental y, por lo tanto, abogó por una integración comprometida con los Derechos Humanos y civiles ${ }^{13}$. Es por ello que la observancia de los principios democráticos conforman una parte importante de la identidad constitucional; en el caso Solange I, el Tribunal Constitucional Federal diagnosticó un déficit a nivel europeo a este respecto. Este hecho fue evidenciado bajo la premisa de que la Comunidad Europea no disponía de un parlamento directamente elegido por sufragio universal que poseyera poderes legislativos y

11 Cf. Sentencias del Tribunal Constitucional Federal (Entscheidungen des Bundesverfassungsgerichts BVerfGE 22, $293<296>$.

12 Cf. BVerfGE $37,271<279$ y $280>$

13 Cf. BVerfGE loc. cit. $<280>$. 
ante el que los órganos facultados para legislar fueran plenamente responsables ${ }^{14}$. Con respecto a la distribución de competencias entre la Comunidad y los Estados miembros, el Tribunal subrayó, en el caso Kloppenburg de 1987, que la transferencia de competencias no podía llevar a una renuncia de la soberanía al ser los Estados miembros «dueños de los tratados» ${ }^{15}$. De este modo se puso de relieve que, en virtud del principio de atribución, la Comunidad Europea solo podía regular aquellas materias cuya competencia hubiese sido transferida y siempre que respetase el principio de subsidiariedad.

Estos requisitos esenciales desarrollados vía jurisprudencial fueron, con posterioridad, codificados y especificados con más detalle a través de una reforma constitucional que incluyó la denominada «cláusula de salvaguarda estructural» (Struktursicherungsklausel) en el artículo 23 de la Ley Fundamental. A través de esta cláusula se exigía que la Comunidad Europea observase los principios democráticos, constitucionales, sociales y federales, y que respetase el principio de subsidiariedad así como un nivel de protección de los Derechos Humanos comparable al proporcionado por la Ley Fundamental.

\section{Validación y garantía del desarrollo de la ley por parte del TJUE}

En contra de las frases comúnmente escuchadas como «la guerra de los jueces ${ }^{16} \mathrm{o}$ «la lucha por la última palabra» ${ }^{17}$, el Tribunal Constitucional Federal, en una etapa temprana, validó y aseguró constitucionalmente la competencia del Tribunal de Justicia de las Comunidades Europeas (TJCE, actual Tribunal de Justicia de la Unión Europea — TJUE_- ) para desarrollar el derecho y enfatizó el papel fundamental del Tribunal de Justicia en la evolución de la comunidad jurídica $^{18}$. Esto me lleva al segundo punto.

A comienzos de los años sesenta, el TJCE asumió la tarea de «garantizar el respeto del derecho en la interpretación y aplicación de los tratados» (Art. $19 \mathrm{sec}$. 1 Tratado de la Unión Europea - TUE) de una manera particularmente abierta a la integración. Al complementar y seguir desarrollando el derecho en sus pronunciamientos, el TJCE promovió la integración y, por lo tanto, reforzó su posición dentro del sistema institucional europeo ${ }^{19}$.

Un primer hito para el TJCE fue su decisión en el caso van Gend E Loos en 1963. En este sentido, el Tribunal liberó a la Comunidad de su corsé clásico en

14 Cf. BVerfGE loc. cit.

15 Cf. BVerfGE 75, $223<242>$.

16 Karpenstein, entrevista en Deutschlandfunk radio el 10 de agosto de 2009, última consulta el 1 de octubre de 2015 en www.dlf.de.

17 Cf., en este sentido, Schwarze, 2005 (3459).

18 Para un extenso estudio sobre este punto cf. F. C. Mayer, 2005 (456 y ss.).

19 Expresamente, e.g., Grimm, 2014 (1047 y ss.). Cf. además, por ejemplo, Tamm, 2013, (22 y ss.). 
virtud del Derecho internacional y postuló que, en lo que respecta a los Estados miembros, el Derecho Comunitario constituía un ordenamiento jurídico independiente y directamente aplicable en los Estados miembros sin la necesidad de una medida nacional de ejecución ${ }^{20}$. Un año más tarde, en la sentencia Costa $v$ E.N.E.L., el TJCE continuó desarrollando su jurisprudencia en una línea pro europea y decidió que en casos de colisión entre el Derecho de la Unión, directamente aplicable, y el derecho nacional, el primero tendría preferencia ${ }^{21}$. Ambas decisiones simbolizan cómo funciona la integración por medio de la jurisprudencia: el ordenamiento jurídico europeo se abre a los ciudadanos y les otorga tanto Derechos como Libertades Fundamentales que pueden hacer valer incluso ante los órganos nacionales. También establece las condiciones necesarias para la libre circulación transfronteriza de mercancías, personas, servicios y capitales, como consecuencia del surgimiento de interdependencias económicas, sociales y culturales elementales para el logro de los objetivos de la Unión Europea, a saber, paz, libertad y prosperidad. Al mismo tiempo, el principio de primacía permite la coordinación de grandes cuerpos jurídicos entre el Derecho de la Unión y el derecho nacional y garantiza una aplicación coherente del derecho.

A nivel nacional, el Tribunal Constitucional Federal no puso freno al TJCE como «motor de integración» sino que incluso lo alentó reconociendo, en ocasiones, su jurisprudencia. En 1967 estuvo de acuerdo con la calificación del Derecho Comunitario como orden jurídico distinto del derecho internacional y nacional ${ }^{22}$. Además, en $1971^{23}$, y por tanto relativamente pronto en comparación con los tribunales constitucionales de otros países ${ }^{24}$, validó y garantizó constitucionalmente el principio de precedencia del Derecho Comunitario, aunque eligió un razonamiento jurídico dogmático diferente al TJCE. Por último, en 1987, con carácter general y por primera vez, expresamente aceptó el desarrollo jurisprudencial del derecho por parte del TJCE, citando la tradición centenaria de creación jurisprudencial del derecho en Europa, que abarca desde el Derecho Romano al Derecho Laboral Alemán ${ }^{25}$.

Ahora bien, la tarea de velar por la aplicación de la legislación europea y nacional corresponde principalmente a las administraciones y a los tribunales nacionales. Debido al modelo de aplicación descentralizada, los tribunales nacionales ordinarios son actores importantes en la aplicación del Derecho de la Unión ${ }^{26}$. A este respecto, el procedimiento prejudicial, con arreglo al art. 267 del

20 Cf. TJCE, Sentencia de 5 de febrero de 1963, Asunto 26/62 (van Gend \& Loos v Netherlands Inland Revenue Administration), European Court Reports - ECR 1963, $1<25>$.

21 Cf. TJCE, Asunto C-6/64 (Costa v. E.N.E.L.), ECR 1964, $1251<1270>$.

22 Cf. BVerfGE 22, $293<296>$.

23 Cf. BVerfGE 31, $145<174$ y $175>$.

24 Para un análisis jurídico comparado, cf. Grabenwarter, 2009 (124 y ss.).

25 Cf. BVerfGE $75,223<242$ y ss. $>$.

26 Con más detalle: Gärditz, 2004 (para. 1). 
Tratado de Funcionamiento de la Unión Europea (TFUE), es absolutamente fundamental para la legitimación del proceso de integración europeo ${ }^{27}$. Y garantiza la obligación de los tribunales nacionales de otorgar prioridad al Derecho de la Unión sobre la legislación nacional en conflicto, lo que refleja un reparto de competencias en la que los dos niveles, el Derecho de la Unión y el nacional, están vinculados ${ }^{28}$.

\section{La puesta en marcha de la obligación de remitir un asunto al TJUE}

El procedimiento prejudicial sería, en cierto modo, ineficaz si la obligación de remitir una asunto al TJUE no estuviera sujeta a revisión. Así, el Tribunal Constitucional Federal se ha esforzado, desde el principio — y este es mi tercer punto-, por su realización constitucional ${ }^{29}$. Este ha declarado que infringiría la garantía del juez legal del art. 101.1 (frase 2) de la Ley Fundamental el no cumplimiento de la obligación de los tribunales alemanes de hacer uso de la cuestión prejudicial. Por lo tanto, las partes tienen derecho a que el TJUE resuelva un asunto conforme a la legislación europea. De hecho, en caso de que la obligación de remitir un asunto sea tratada de manera manifiestamente insostenible por un tribunal, la decisión puede ser impugnada ante el Tribunal Constitucional Federal.

Esto demuestra que la interacción del Tribunal Constitucional Federal con el Tribunal de Justicia se lleva a cabo en colaboración. De este modo, a principios del año pasado, en el contexto del programa de transacciones monetarias directas del BCE (OMT), la Sala Segunda del Tribunal Constitucional Federal planteó, por primera vez en la historia de este tribunal, varias cuestiones prejudiciales al Tribunal de Justicia ${ }^{30}$.

\section{Impulsos para el desarrollo de la protección de los Derechos fundamentales}

Esto me lleva a otro importante impulso legitimador. A pesar de los límites establecidos por el Tribunal Constitucional Federal a la primacía del Derecho de la Unión, lo que a primera vista parecía una ralentización del proceso de integración jurídica, finalmente promovió el proceso y su jurisprudencia ha

27 Expresamente, e.g., Skouris, 2008 (344 y ss.) and Karpenstein, 2014 (para. 1). Cf. Además, e.g., Proelss, 2014, (pp. 172 y ss.) con nuevas referencias.

28 Con más detalle: Voßkuble, 2010a (1 y ss.). Cf. también Ludwigs, 2014 (273 y ss.). Crítico, por ejemplo, Biaggini, 2014 (29 y 30).

29 Con más detalle: Britz, 2012 (1313 y ss.). Véase Voßkuble/Lange, 2014 (paras. 19 y ss.) con nuevas referencias.

30 Cf. BVerfGE 134, 366. 
dado impulsos decisivos para el desarrollo de la protección de los Derechos Fundamentales en la Unión. El punto de partida lo conformó la decisión Solange I de 1974, mencionada anteriormente. En esta decisión, el Tribunal Constitucional Federal restringió aún más la primacía del Derecho de la Unión en los casos que estuviera en conflicto con los Derechos Fundamentales de la Ley Fundamental ${ }^{31}$. Sobre la base de su propia comprensión como tribunal de los ciudadanos, el Tribunal Constitucional Federal tenía como objetivo reforzar la protección de los Derechos Fundamentales como elemento básico del estado de Derecho a nivel de la Unión Europea ${ }^{32}$. El TJCE aceptó este desafío y, desde principios de los años setenta, ha elaborado sistemáticamente un catálogo no codificado de Derechos Fundamentales, invocando las tradiciones constitucionales comunes a los Estados miembros y el Convenio Europeo de Derechos Humanos $^{33}$. En este contexto, en 1986, el Tribunal Constitucional Federal, en su sentencia Solange II, sostuvo que la condición establecida en la decisión Solange I se había cumplido en lo esencial. Y, por lo tanto, el Tribunal Constitucional Federal sólo ejercería su competencia cuando no pueda garantizarse en el Derecho de la Unión un nivel de protección esencialmente equivalente al previsto por la Ley Fundamental ${ }^{34}$.

Por su parte, la jurisprudencia del TJCE sobre los Derechos Fundamentales de la Unión dio un importante impulso a la elaboración de un catálogo de Derechos Fundamentales recogido en la Carta de los Derechos Fundamentales (CDFUE), que entró en vigor el 1 de diciembre de 2009.

En la actualidad, el equilibrio del sistema de protección de los Derechos Fundamentales amenaza con hacerse menos estable. En su sentencia Akerberg Fransson de 2013, el Tribunal de Justicia de la Unión Europea (TJUE) interpretó una disposición sobre el alcance de la Carta (artículo 51.1 CDFUE) de forma tan amplia que prácticamente cualquier acto de un Estado miembro vinculado al Derecho de la Unión podría estar sujeto a su revisión de los Derechos Fundamentales ${ }^{35}$.

A modo de respuesta, el Tribunal Constitucional Federal en una sentencia, de abril de 2013, sobre la base de datos antiterrorista, advirtió que la decisión de Akerberg no debía aplicarse de una manera que entendiese que la CDFUE fuera

31 Cf. BVerfGE $37,271<285>$.

32 Cf. Limbach, 2001 (2916).

33 Cf., e.g., TJCE, 11/70 (Internationale Handelsgesellschaft v. Einfuhr- und Vorratsstelle für Getreide und Futtermittel), ECR 1970, $1125<1135>$.

34 BVerfGE 73, $339<376,387>$ - Solange II; seguido en BVerfGE 89, $155<174$ y $175>$ - Maastricbt; BVerfGE 102, $147<167>$ — organización común de mercados en el sector del plátano; BVerfGE 123, 267 $<335>-$ Tratado de Lisboa.

35 TJUE, Sentencia de 26 de febrero de 2013, C-617/10 (Åkerberg Fransson), NJW 2013, pp. 561 y 562 paras. 17 a 27; cf. en lo que respecta a las críticas sobre la interpretación del TJUE del art. 51 de la CDFUE, e.g., Frenzel, 2014 (18 y ss.). Sobre la necesidad de que el TJUE concrete el criterio de «aplicación» del Derecho de la Unión cf. Hancox, 2013 (1425 y ss.). La jurisprudencia posterior desarrollada por las Salas del TJUE no está clara, cf., e.g., Franzius, 2015a (390) con nuevas referencias. 
vinculante tan pronto como pudiera establecerse cualquier conexión abstracta o producirse efectos puramente incidentales sobre el Derecho de la Unión ${ }^{36}$. La finalidad del Tribunal Constitucional Federal es, por lo tanto, mantener una protección efectiva de los Derechos Fundamentales a nivel europeo, pues existe el riesgo de que, a causa de un cambio general de la protección de los Derechos Fundamentales desde el nivel nacional al supranacional, se otorgue una protección supuestamente mayor pero a expensas de la precisión y la proximidad de los casos. En las relaciones «multipolar» de Derechos Fundamentales, en las que deben equilibrarse varias posiciones de Derechos Fundamentales, también pueden surgir conflictos si el Tribunal de Justicia determina que una posición de Derechos Fundamentales de la Carta prevalece sobre un Derecho Fundamental nacional opuesto ${ }^{37}$.

Independientemente de esto, tampoco debe descuidarse el siguiente aspecto: la centralización de la protección de los Derechos Fundamentales en un solo tribunal sería contraria a la conceptualización de una comunidad jurídica federal con responsabilidades compartidas. Ello conduciría potencialmente a la uniformidad en diversas cuestiones jurídicas, desde la protección de datos al derecho de seguros pasando por el Derecho penal, lo que no es totalmente compatible con el reparto de competencias y, por tanto, es disconforme a la voluntad de los Estados miembros. Este «igualitarismo formalista ${ }^{38}$ a través del derecho reduce los márgenes políticos de maniobra y se impondría a una protección equilibrada, que ha ido evolucionando históricamente, de los Derechos Fundamentales en los Estados miembros $^{39}$. Todo ello podría tener un efecto bastante desintegrador y contrario a los objetivos de la Unión.

En este contexto, tampoco parece oportuna una hipotética fusión de las esferas de los Derechos Fundamentales. La propuesta para que el Tribunal Constitucional Federal examine un caso, en primer lugar, con arreglo a los aspectos esenciales del derecho recogido en la Ley Fundamental y en lo que se refiere a la sustancia, teniendo a su vez en cuenta las normas de la CDFUE y del Convenio Europeo de Derechos Humanos (CEDH) para, en caso de conflicto, dar prioridad al Derecho de la Unión ${ }^{40}$, solo sería aceptable si el Tribunal de Justicia tuviera que ejercer un control riguroso $^{41}$ para lo cual, a mi juicio, existen muy pocos indicios en la actualidad ${ }^{42}$.

36 BVerfGE 133, $277<316$ para. 91 >. Para una reconstrucción matizada de la jurisprudencia del Tribunal Constitucional Federal cf. Britz, 2015, (275 y ss.) con nuevas referencias.

37 Lange, 2014 (173).

38 Hallstein, 1962 (347).

39 Expresado claramente en Masing, 2015 (486). Además, cf. Obler, 2013 (1438). Sobre el pluralismo de los derechos fundamentales en general, véase, por ejemplo, las contribuciones en: Avbelj/Komárek, 2012.

40 En este sentido: Thym, 2015 (57). Para un enfoque más radical cf. Bäcker, 2015 (410 y ss.). Para un análisis instructivo del debate cf. Franzius, 2015 a (383 y ss.).

41 En la misma línea también Franzius, 2015b (152).

42 Un caso ejemplar, por ejemplo, la sentencia del TJUE de 14 de octubre de 2004, C-36/02 (Omega), ECR 2004, p. I-9609, paras. 23 y ss.; sobre una revisión de los derechos fundamentales por el TJUE que se ejerce con moderación tras la decisión Solange II cf. F. Kirchbof, 2014 (272). 
Al mismo tiempo, la complejidad de la protección multinivel de los derechos fundamentales en el sistema europeo no debe disuadirnos. Lo mismo sucede con respecto a la adhesión de la Unión Europea al CEDH, tal como se contempla en el art. 6.2 TUE, como consecuencia de la cual, los actos jurídicos y las resoluciones judiciales de los órganos de la Unión estarían sujetos a un control jurisdiccional por parte del Tribunal de Estrasburgo. Sin embargo, en su dictamen de 18 de diciembre de $2014^{43}$, el TJUE llegó a la conclusión de que el proyecto de acuerdo sobre la adhesión de la Unión Europea al Convenio Europeo para la Protección de los Derechos Humanos y de las Libertades Fundamentales no era compatible con el Derecho primario europeo ${ }^{44}$. Queda abierta, por tanto, la posibilidad de que la doctrina reproche esta decisión del TJUE para asegurar su propia prerrogativa de interpretación sobre cuestiones relativas a los Derechos Fundamentales de la UE ${ }^{45}$. Lo que sí podemos afirmar es que la inclusión de un tribunal internacional especializado en Derechos Humanos aumentaría la legitimidad y la credibilidad del sistema de protección de los Derechos Humanos en su conjunto.

\section{Asegurar la observancia de la agenda de integración europea}

Además de la revisión de los derechos fundamentales, el Tribunal Constitucional Federal ha desarrollado dos instrumentos adicionales, como se acordó en los Tratados europeos, destinados a asegurar la agenda de la integración europea: la revisión de la identidad y la revisión ultra vires ${ }^{46}$.

Mediante la revisión de la identidad, el Tribunal Constitucional Federal examina si se ha respetado el núcleo inalienable de la Ley Fundamental (art. 23. 1 en relación con el artículo 79.3 de la Ley Fundamental). El art. 23.1 de la Ley Fundamental establece expresamente límites a la transferencia de derechos soberanos a la Unión Europea. En consecuencia, como se ha mencionado, los fundamentos estructurales de nuestro Estado, tales como el principio democrático, el estado de bienestar social, la república y el federalismo, no pueden ser abandonados. Lo mismo sucede con la garantía de la dignidad de la persona y con aquellos derechos fundamentales que, para decirlo sucintamente, son parte integrante de la

43 Dictamen (2/13) del TJUE (Pleno) de 18 de diciembre de 2014, Diario Oficial de la Unión Europea C 65 de 23 de febrero de 2015, p. 2.

44 Un análisis crítico del dictamen en Wendel, 2015 (921).

45 Cf. F.C. Mayer, 2015a (122); Tomuschat, 2015 (137 y 139); Schorkopf, 2015 (783).

46 Cf.BVerfGE 134, $366<382$ y ss., paras. 22 y ss. > resumiendo su jurisprudencia anterior. Una descripción de la evolución de estos dos instrumentos para conservar la competencia de revisar determinados actos y su recepción por los tribunales de los demás Estados miembros cf., por ejemplo, Wendel, 2011 (462 y ss., 471 y ss.) con referencias adicionales, respectivamente. Kahl, 2013, (197 y ss.), en los que se subraya, acertadamente, la función compensatoria de estos dos instrumentos. Sin embargo, últimamente se ha ido tomando una postura crítica, por ejemplo, por Schwerdtfeger, 2015 (290 y ss.). 
dignidad humana ${ }^{47}$. Se aplica lo siguiente: lo que está más allá del alcance de la Constitución tampoco está abierto a la integración ${ }^{48}$. Los actos jurídicos europeos que afectan a este núcleo inalienable de la Constitución no son aplicables en Alemania ${ }^{49}$. Por lo tanto, la integración y la identidad están mutuamente vinculadas. Son dos caras de la misma moneda, dos valores que deben protegerse constitucionalmente y con arreglo a la legislación de la Unión, cuya salvaguardia y promoción van de la mano. Esto se deriva, en particular, del propio art. 4.2 TUE: «La Unión respetará la igualdad de los Estados miembros ante los Tratados, así como su identidad nacional, inherente a las estructuras fundamentales políticas y constitucionales de éstos, también en lo referente a la autonomía local y regional» ${ }^{50}$.

La revisión ultra vires se distingue de la revisión de la identidad. Esta se basa en la idea de que la Unión, a diferencia de un Estado, no puede generar competencias propias. En virtud del artículo 5.2 TUE, los Estados miembros han obligado a las instituciones de la Unión a respetar los límites de las competencias atribuidas. Una aplicación teleológica de las normas de competencia, guiada principalmente por el objetivo de la funcionalidad y la eficiencia de la Unión y que no esté sujeta a un control judicial eficaz ${ }^{51}$, corre el riesgo de socavar la agenda de integración convenida contractualmente y, en última instancia, de dar la espalda al derecho, lo que conduciría a la desintegración. Por ello, la revisión ultra vires pretende limitar el traspaso de las fronteras ${ }^{52}$.

Ya en su sentencia Maastricht de 1993, el Tribunal Constitucional Federal reservó su propia competencia para evaluar si los actos jurídicos de las instituciones y órganos europeos se encontraban dentro de esos límites o, por el contario, fuera de ellos $^{53}$. En la Sentencia Lisboa de 2009, el Tribunal Constitucional Federal, por primera vez, se refirió a un examen ultra vires y restringió, de una forma abierta, su ejercicio en el Derecho europeo ${ }^{54}$. En la decisión Honeywell, de 6 de julio de 2010, el Tribunal Constitucional Federal especificó, además, este requisito de apertura al Derecho europeo. En primer lugar, consideró que antes de declarar que un acto es ultra vires, debe darse al Tribunal de Justicia, en un procedimiento prejudicial, la oportunidad de interpretar el Tratado y pronunciarse sobre la validez y la interpretación de los actos de que se trata ${ }^{55}$. En segundo lugar, indicó que la revisión ultra vires sólo tiene lugar si existe un exceso manifiesto de las competencias ejercidas por

47 Cf. BVerfGE 123, $267<348>$.

48 Cf. BVerfGE loc. cit.

49 Cf. BVerfGE 123, $267<400>$; 126, $286<302>$.

50 Con mayor detalle, cf., e.g., Wischmeyer, 2015 ( 415 y ss.) con nuevas referencias.

51 Cf. Klein, 2014 (185).

52 Ver también Ludwigs, 2015 (537).

53 BVerfGE 89, $155<188,209$ y 210>; ver también BVerfG, Resolución de la Primera Cámara de la Sala Segunda de 17 de febrero del 2000 - 2 BvR 1210/98 — NJW 2000, p. $2015<2016>$ — Alcan; de las muchas voces críticas de la doctrina legal, ver, a modo de ejemplo, Zuleeg, 1994, (3 y ss.).

54 BVerfGE $123,267<354>$.

55 Un punto de vista crítico sobre la solicitud de cuestión prejudicial en este caso: P. Kirchbof, 2013, (5). 
las instituciones europeas y que, a su vez, se traduzcan en un cambio estructural significativo a expensas de las competencias de los Estados miembros ${ }^{56}$.

La primera vez que el Tribunal Constitucional Federal accedió a enjuiciar un asunto de este tipo fue a propósito de una decisión del Consejo de Gobierno del Banco Central Europeo (BCE) que permitía la compra de bonos de determinados Estados miembros sin ninguna limitación (conocida como la decisión OMT) ${ }^{57}$ y — como ha sido mencionado_- se remitió una cuestión prejudicial al TJUE para conocer si la decisión OMT era compatible con el mandato de política monetaria del BCE (cf. Art. 119 y 127 y ss. TFUE) o si, por el contario, violaba la prohibición de la financiación monetaria del presupuesto (Cf. Art. 123.1 TFUE). En su sentencia de 16 de junio de $2015^{58}$, el Tribunal de Justicia respondió negativamente a estas dos cuestiones prejudiciales. Sin embargo, al mismo tiempo, subrayó que, contrariamente a las presunciones de los Estados miembros y de una parte de la doctrina ${ }^{59}$, los actos del BCE también están sujetos a límites susceptibles de revisión judicial, entre ellos, la prohibición de financiación monetaria del presupuesto $^{60}$. Con su resolución de 21 de junio de 2016, la Sala Segunda ha decidido que el hecho de que el Gobierno Federal y el Bundestag se hayan abstenido de tomar medida alguna, sea de abolición o de limitación, con respecto a la decisión básica del Banco Central Europeo de 6 de septiembre de 2012, sobre las medidas apropiadas al programa OMT, no viola los derechos de la demandante; condicionado todo ello a que, como estableció el Tribunal de Justicia en su cuestión prejudicial, se cumplan las limitaciones de las medidas relacionadas con el alcance de dicho programa. A partir de estas premisas, el programa OMT no interfiere en la libertad presupuestaria del Bundestag.

El ejemplo del método OMT ilustra muy claramente la forma en que interactúa la protección del Tribunal Federal Constitucional y del Tribunal de los Derechos Fundamexntales y muestra claramente que la garantía del cumplimiento del programa de integración se puede asegurar de una manera amistosa por parte del Tribunal Constitucional Federal.

\section{El principio de apertura al Derecho europeo}

Como se ha explicado anteriormente, las competencias de revisión del Tribunal Constitucional Federal para salvaguardar la integración quedan

56 BVerfGE $126,286<303$ y ss. $>$.

57 Cf. BVerfGE 134, 366.

58 TJUE, Sentencia de 16 de junio de 2015 - C-62/14 (Gauweiler and Others) JZ 2015, pp. 785 y ss.

59 Desde un punto de vista crítico: Schmidt, 2015 (326) con referencias adicionales.

60 Se recalca, de forma positiva, que las competencias del BCE fueron restringidas por el derecho: $F$. C. Mayer, 2015 (2002 y 2003). Con una misma vision: Obler, 2015 (1004 y ss.). Relativizando esta visión, sin embargo: Klement, 2015 (754 and 755). 
limitadas a excepciones manifiestas. La razón de ello se basa en la sujeción del ejercicio de estas competencias al principio de apertura al Derecho europeo. Este principio, desarrollado por el Tribunal Constitucional Federal en la sentencia Lisboa, deriva del mandato constitucional para la consecución de una Europa unida recogido en el art. 23.1 de la Ley Fundamental así como en su preámbulo. Es por ello que el principio de apertura al Derecho europeo puede considerarse una prueba más de la posición pro-integración del Tribunal Constitucional Federal en su jurisprudencia. De acuerdo con este, la Ley Fundamental exige la participación en el proceso de integración europea, y en el orden de paz internacional ${ }^{61}$, de todos los órganos constitucionales, incluido el Tribunal Constitucional Federal y, por lo tanto, deberán actuar conforme a este principio. Todavía no se puede prever cuanta influencia tendrá el postulado de apertura al Derecho europeo en casos individuales. Sin embargo, si se consideran otros principios generales como, por ejemplo, el effet utile —un método que el TJUE emplea en la interpretación del Derecho de la Unión para alcanzar el mayor grado posible de eficacia práctica - no se debe subestimar su influencia. En cualquier caso, el principio de apertura al Derecho europeo no constituye, simplemente, una promesa no vinculante, de buena voluntad, en materia de integración europea.

\section{El concepto de responsabilidad en relación con la integración}

Debe quedar cada vez más claro que los organismos gubernamentales se enfrentan a un difícil equilibrio en la aplicación de la idea de comunidad jurídica. Por un lado, promover el proceso de integración de acuerdo con la apertura de la Ley Fundamental al Derecho europeo y, por otro, preservar la identidad constitucional nacional ${ }^{62}$. Con el fin de evitar una dinámica unilateral que entrañase un riego de incumplimiento, bien del Derecho de la Unión o de la legislación nacional, el Tribunal Constitucional Federal se esforzó por dar efecto, en la sentencia Lisboa, al concepto de responsabilidad en materia de integración europea ${ }^{63}$. En base al mismo, la responsabilidad en materia de integración significa asumir un compromiso duradero y sostenible respecto a la integración europea, primero en la transferencia de competencias soberanas y el desarrollo de los procedimientos europeos de toma de decisiones ${ }^{64} \mathrm{y}$, posteriormente, en el desarrollo dinámico de

61 Cf. BVerfGE $123,267<346$ y $347>$.

62 Señalado acertadamente por Lenaerts, 2015 (353): «Therefore, neither uniformity nor diversity can lay claim to absolute validity. The European Union must continuously take into account both aspects, since neither of them alone suffices to secure the integration project.»

63 BVerfGE 123, 267 — nota 2. Con más detalle: Voßkuble, 2010b (229 y ss.); Nettesheim, 2010 (177 y ss.); Calliess 2012 (55 y ss.); desde un punto de vista crítico: von Bogdandy, 2010 (3).

64 BVerfGE loc. cit. p. 356. 
los Tratados y su posterior aplicación administrativa ${ }^{65}$. En suma, se trata de legitimar el proceso que acompaña a la integración. Además de a las instituciones de la Unión Europea, la responsabilidad en materia de integración incumbe a todos los Estados miembros y a sus órganos constitucionales ${ }^{66}$. En su resolución de remisión en el asunto OMT, el Tribunal Constitucional Federal enumeró ejemplos de los requisitos concretos que podrían resultar de ello. Así, como consecuencia de la responsabilidad con respecto a la integración, el Bundestag y el Gobierno Federal están obligados a velar por el cumplimiento del programa de integración. Mientras que, por el contario, en los casos de superación manifiesta y estructural de las competencias por parte de las instituciones europeas, éstas no sólo deben abstenerse de actos de participación o de ejecución, sino que también deben trabajar activamente para el cumplimiento del programa de integración.

\section{El fortalecimiento de la integración de los parlamentos en los procesos de toma de decisiones políticas europeas}

En particular, desde el inicio de la crisis de la deuda soberana están en juego fuerzas que, sobre la base de la máxima: «la necesidad carece de ley», buscan resolver problemas fuera del alcance de los requisitos legales, a nivel político ${ }^{67}$. En lugar de hacer uso, por parte del ejecutivo, de procedimientos parlamentarios transparentes en la gestión de crisis políticas a corto plazo, se decide con rapidez teniéndose en cuenta intereses y limitaciones muy diversas. En varias decisiones, el Tribunal Constitucional Federal ha pedido, en este sentido, la democratización de los procesos políticos europeos de toma de decisiones lo que fortalecería la legitimación de la integración ${ }^{68}$.

Ya en la sentencia Mastricht de 1993, el Tribunal Constitucional Federal señaló que, en la construcción europea, la legitimación democrática también resulta necesariamente de la participación de los parlamentos de los Estados miembros en los actos de las instituciones europeas ${ }^{69}$.

Las decisiones en el contexto de la crisis de deuda soberana se refieren principalmente a la garantía de soberanía presupuestaria del Parlamento. En su decisión sobre la ayuda a Grecia y el plan de rescate del Euro (septiembre de 2011), el Tribunal Constitucional Federal determinó que un parlamento no debe renunciar a su margen de actuación en el ámbito financiero. Por lo tanto, la competencia de

65 BVerfGE loc. cit. p. 435.

66 Ver también BVerfGE 134, $366<395$ para. 48> con más referencias.

67 Referencias críticas, además de las mencionadas en la nota 6, por ejemplo: Müller-Franken, 2015 (356 y ss.).

68 Recientemente, con más detalle: Daiber, 2014 (809 y ss.) con más referencias. Sobre esta línea general jurisprudencial ver Emmenegger, 2011, (447 y ss.).

69 Cf. BVerfGE 89, $155<185>$. 
toma de decisiones en materia de ingresos y gastos públicos debía permanecer en el Bundestag alemán ${ }^{70}$. Entendió que el derecho a decidir sobre el presupuesto constituye un elemento central para el desarrollo de la voluntad democrática. Así, el Bundestag debe aprobar específicamente todas las medidas de ayudas a gran envergadura llevadas a cabo por el Gobierno Federal conforme al espíritu de solidaridad y que impliquen un gasto público a nivel internacional o de la Unión Europea $^{71}$.

El proceso de toma de decisiones no puede estar estructurado de manera que excluya del ejercicio de la responsabilidad presupuestaria global a una gran parte de los miembros del Parlamento. La confidencialidad o urgencia a la hora de tomar medidas de emergencia, por ejemplo, para superar la crisis de la deuda soberana, no justifica la delegación de la toma de decisiones a órganos subsidiarios. En una sentencia de 2012, el Tribunal Constitucional Federal concluyó que la delegación en una comisión especial del Bundestag, integrada por nueve miembros, no estaba justificada. A este Comité se le había delegado la facultad de ejercer, con carácter excepcional, los derechos de participación parlamentaria en los asuntos relativos al Fondo Europeo de Estabilidad Financiera, predecesor del Fondo de Rescate Permanente y conocido con el nombre de Mecanismo Europeo de Estabilidad (MEDE) ${ }^{72}$. Con respecto al fondo de rescate permanente, el MEDE, el Tribunal Constitucional Federal, en septiembre de 2012, rechazó las solicitudes de una medida cautelar que prohibiera al Presidente Federal firmar los documentos de aprobación del $\mathrm{MEDE}^{73}$. En un examen sumario, el Tribunal Constitucional Federal afirmó la constitucionalidad de la Ley de aprobación del Tratado MEDE. Sin embargo, no se limitó a «dejar pasar» esta medida de rescate sino que para su ratificación estableció, entre otras cosas, una condición que, en virtud del Derecho internacional, limitaba las obligaciones de pago de la República Federal de Alemania a 190.000 millones de Euros. En este sentido, ninguna disposición del Tratado podría interpretarse de manera que estableciera obligaciones de pago más elevadas para la República Federal de Alemania sin el consentimiento del representante alemán en los órganos del $\mathrm{MEDE}^{74}$. Esto, a su vez, significa la imposibilidad de aumentar la responsabilidad económica de la República Federal sin la renovada aprobación del Bundestag. Al mismo tiempo, el Tribunal Constitucional Federal sostuvo que el «Pacto Fiscal», que obliga a las partes a introducir un freno en la capacidad de endeudamiento, es

70 Cf. BVerfGE 129, $124<177>$, cf., por ejemplo, el resumen del análisis de las normas para la concesión de la ayuda a Grecia por Kube, 2012 (205 y ss.).

71 Sobre este tema en su conjunto cf. BVerfGE loc. cit. p. 180. Para un análisis de la protección de la soberanía presupuestaria véase, por ejemplo, Nettesheim, 2011 (771); Ruffert, 2011 (847 y ss.). Véase, también, la norma establecida en la BVerfGE $132,195<238$ y ss., paras. 105 y ss. $>$.

72 Cf. BVerfGE 130, 318.

73 BVerfGE 132, 195 y ss. Cf. Sobre esto Herrmann, 2012 (805 y ss.); Kabl, 2013 (197); Lepsius, 2012 (761 y 762); Müller-Franken, 2012 (3162 y ss.) (comentario de la sentencia BVerfGE 132, 195); Schorkopf, 2012 (1273 y ss.); Tomuschat, 2012 (1431 y ss.).

74 BVerfG, loc. cit., p. 257 para. 149. 
compatible con el principio democrático. Por último, en la sentencia sobre el Tratado ESM y el Pacto Fiscal de 18 de marzo de 2014 el Tribunal de Justicia siguió la línea expuesta en su resolución prejudicial ${ }^{75}$.

\section{Efectos anticipados de la jurisprudencia del Tribunal Constitucional Federal}

En particular, a través del contexto de las medidas de rescate europeas se ha puesto de manifiesto otro importante impulso legitimador de las decisiones del Tribunal Constitucional Federal: los efectos anticipados de su jurisprudencia. Que fuera posible, en el contexto de gestión de una crisis, la aprobación del MEDE y el Pacto Fiscal constituye un éxito considerable para el ideal del derecho. En una situación muy difícil, la política se mostró en contra de los acuerdos informales ad hoc y, por el contario, optó por la legitimación y la reinserción democrática de los instrumentos relacionados con la crisis. La especulación sobre la labor de la jurisprudencia del Tribunal Constitucional Federal en el aseguramiento de la soberanía presupuestaria del parlamento parece obvio si examinamos de cerca los diferentes elementos que configuran el mecanismo de estabilidad. El Tratado MEDE, por ejemplo, para salvaguardar la responsabilidad presupuestaria global de los Parlamentos nacionales estipula un límite a las obligaciones de pago y fija que, en asuntos presupuestarios claves, las decisiones no pueden tomarse con el voto en contra de los representantes de los Estados miembros que asumen la carga principal de las medidas de ayuda financiera.

La obligación de los Estados miembros, establecida en el Pacto Fiscal, de presentar un presupuesto equilibrado e introducir una limitación a la capacidad nacional de endeudamiento toma también elementos de la jurisprudencia del Tribunal Constitucional Federal. Estos tienen por objeto mantener la disciplina presupuestaria y, por lo tanto, tener en cuenta la exigencia constitucional de salvaguarda de la soberanía presupuestaria de los parlamentos.

\section{Una visión realista del derecho}

El último punto que quiero destacar en el contexto actual es la visión realista del derecho en las decisiones del Tribunal Constitucional Federal en materia de integración. Esta visión facilita la comprensión de la redacción, el funcionamiento y los déficits de los Tratados Europeos. Por regla general, la crisis y los conflictos constituyen una prueba decisiva para el derecho. Por lo tanto, el Tribunal Constitucional Federal a menudo piensa en términos del «peor escenario». En la sentencia de Maastricht, por ejemplo, señaló que el fracaso de los esfuerzos para lograr la estabilidad

75 Cf. BVerfGE 135, 317. 
podría conducir a concesiones fiscales de los Estados miembros con consecuencias imprevisibles en toda la Unión Europea ${ }^{76}$. En su sentencia Lisboa determinó que, entre otras cosas, la norma democrática básica de igualdad en el Derecho electoral («un hombre, un voto») no se cumplía a nivel europeo, con consecuencias para la legitimación democrática de las decisiones y su aceptación ${ }^{77}$. En la decisión sobre el MEDE ordenó al Gobierno Federal cubrir las lagunas en lo relativo a la limitación de endeudamiento ${ }^{78}$. En su resolución de remisión al TJUE advirtió que no se eludiría la prohibición de la financiación monetaria del presupuesto (artículo 123.1 TFUE ${ }^{79}$. Esta lista podría ampliarse. Muy a menudo estas y otras declaraciones en los razonamientos han sido percibidas como «agresivas» y «anti-europeas», como evidentemente carente de empatía por el proyecto europeo y sus instituciones. Se dice que todo el estilo del razonamiento, independientemente de los resultados legales, está impregnado de este estilo y, en efecto, el «sonido» de las decisiones del Tribunal Constitucional Federal es, a primera vista, poco atractivo. La extensa y, a menudo, muy detallada exposición de los hechos es seguida por el complejo proceso de obtención de los estándares a aplicar a partir de material normativo existente y la propia jurisprudencia del Tribunal Constitucional Federal con numerosas distinciones y diferenciaciones ${ }^{80}$. Esto va seguido por la aplicación de la ley al caso específico, lo que puede parecer algo más técnico.

Puede dudarse si este estilo marcadamente dogmático ${ }^{81}$ es conforme a los razonamientos y pensamientos de otros tribunales, especialmente en contextos europeos e internacionales, a pesar de la amplia aceptación de la jurisprudencia del Tribunal Constitucional Federal.

Por el contrario, se debe advertir en contra de una retórica europea demasiado acrítica. No puede ser tarea de los tribunales «darle un giro positivo a las cosas» — hablando de manera informal—. Sino que estos deben contribuir, mediante un análisis realista y sobrio del caso a enjuiciar, al reforzamiento de los fundamentos jurídicos de la integración europea.

\section{CONTRACORRIENTE: ¿ESTÁ SOBRECARGADA LA IDEA DE COMUNIDAD JURÍDICA?}

Con este apartado concluye mi tour d'horizon a través de los 50 años de jurisprudencia del Tribunal Constitucional Federal sobre Europa. Se podría decir más

76 Cf. BVerfGE 89, $155<205>$.

77 Cf. BVerfGE $123,267<371$ y $372>$.

78 Cf. BVerfGE 132,195 y ss.

79 Cf. BVerfGE $134,366<411$ y ss. paras. 84 y ss. $>$.

80 Desde un punto de vista crítico: Lepsius, 2011 (59 y ss.).

81 Sobre su origen véase Bumke, 2014 (642 y ss.). Para más detalles sobre la diferenciación entre la dogmática del uso y de la ciencia (Gebrauchs- und Wissenschaftsdogmatik) ver Kaiser, 2014 (1105). 
acerca de cada sentencia, incluyendo críticas. El objetivo principal de este trabajo ha sido trazar una línea de conexión entre las diferentes sentencias. Cada una de estas se ha basado en la fe de la fuerza integradora de la comunidad jurídica europea. «¿iIntegración a través del derecho!?». Pero, ¿no ha alcanzado este concepto, a pesar de su huella jurídica internacional ${ }^{82}$, su límite con la llegada de la crisis financiera y de deuda soberana ${ }^{83}$ No falta escepticismo, como lo ilustran los siguientes puntos que a menudo pueden ser escuchados por los $\operatorname{críticos}^{84}$.

El derecho no aborda las causas reales de la crisis. Debido a su carácter abstracto, debe excluir necesariamente una serie de necesidades y particularidades. Por lo tanto, no se ocupa adecuadamente de la complejidad de la crisis de la deuda soberana y de los múltiples intereses de las partes y los Estados involucrados.

Además, se argumenta que las soluciones de conflicto proporcionadas por el derecho son demasiado rígidas. El derecho es un «código binario» —algo no puede ser «ligeramente ilegal», sería como decir «ligeramente embarazada». Sin embargo, especialmente en tiempos de crisis, se necesitan soluciones y compromisos parciales.

Además, supuestamente ni los legisladores nacionales, europeos o los tribunales pueden reaccionar con la prontitud necesaria, sobre todo porque las modificaciones necesarias de los Tratados a nivel europeo no parecen políticamente viables.

La inmensa complejidad y dinamismo de la crisis de deuda soberana así como los efectos y riesgos, a nivel global, estrechamente vinculados a ella se ha visto como una circunstancia a la que el legislador o los tribunales, debido a la falta de conocimiento, no han sido capaces de dar soluciones razonables ${ }^{85}$. En el mejor de los casos, es el ejecutivo el que probablemente disponga de la información necesaria, e incluso los mejor situados serían las instituciones especializadas, como las distintas agencias europeas, el BCE o el sector privado, por ejemplo.

Y en cualquier caso, según este argumento, muchos actores a nivel europeo no se adhieren al derecho. La aparente violación de los criterios de estabilidad, en particular también por Alemania y Francia, o el incumplimiento de los requisitos de la Convención de Dublín constituyen una prueba excelente ${ }^{86}$. La lista de objeciones podría ampliarse. Sin embargo, en mi opinión, la mayoría de estos argumentos no logran convencer.

82 Cf. nota 9.

83 Expresamente Rodi, 2015 (737): «With the financial crisis the legal dress of the Economic and Monetary Union has become too tight — substantively and institutionally»; además, cf. las contribuciones en Möllers/Zeitler, 2013.

84 Para un profundo debate sobre el tema ver Voßkuble 2015 (137 et seq.) con más referencias.

85 Sobre la «tecnocratización ad hoc» causada por la crisis financiera y la deuda soberana cf. Enderlein, 2013 (724 y ss.).

86 Con más detalle, Palm, 2004 (71 y ss.). 
Ciertamente el hecho de que el derecho deja de considerar muchos aspectos de un conflicto puede percibirse como una incapacidad para lidiar con la complejidad. La gran ventaja de esta distancia, sin embargo, es que permite un grado de abstracción con respecto a la diversidad de personas o Estados. La distancia con los conflictos personales y políticos es una de las fortalezas específicas del derecho. Mediante esta distancia, la ley puede crear una base común aun cuando una comunidad se caracteriza por diferencias culturales. La ley expresa ideas de justicia universalmente aplicables para una comunidad pluralista que, a pesar de todas las diferencias, ha llegado a acuerdos. Por lo tanto, en una Europa diversa, el derecho desempeña un papel muy importante para el proceso de integración europea.

Esto se puede percibir claramente si recordamos las alternativas. ¿Qué pasaría si cada conflicto entre los Estados miembros se decidiera por la vía política?

No solo habría una competición por obtener ventajas a corto plazo sino, también, entrarían en juego todos aquellos factores que, de forma acertada, el derecho no ha tenido en cuenta — por ejemplo, el tamaño y la influencia económica del Estado miembro, el color del partido que esta en el gobierno así como alianzas, afrentas o decepciones pasadas. En un plazo muy breve, la Unión Europea tendría que enfrentarse a una prueba crucial, de la que difícilmente podría sobrevivir. Las negociaciones sobre el rescate griego constituyen un buen ejemplo.

En comparación con los enfrentamientos políticos, la ley ofrece una ventaja significativa: mientras que el acuerdo sobre un marco jurídico es, sin duda, el resultado de un debate político ${ }^{87}$, la ley se establece antes del conflicto. No en todos los casos pero, por regla general, impide la politización de una disputa específica. Esto constituye uno de los logros significativos de integración del Derecho europeo. En opinión de los padres fundadores, la cooperación económica (ie: La Comunidad Europea del Carbón y del Acero) y la cooperación política (ie: la Comunidad Europea de Defensa) estaban destinadas a constituir la base del proceso de integración europeo. Ambos objetivos estuvieron, y siguen estando, sujetos a conflictos de intereses y son consecuentemente frágiles. Solo a través de la fuerza unificadora de los tratados, según palabras de Walter Hallstein, el Estado de derecho reemplaza «al poder y su manipulación $[\ldots .$.$] del equilibrio de$ fuerzas, la lucha por la hegemonía y el juego de alianzas» y elimina «el uso de la fuerza y la presión política» ${ }^{88}$. El establecimiento tanto del MEDE como del Pacto Fiscal, mencionados anteriormente, sirven de ejemplo de cómo la política, incluso en tiempos de crisis, puede actuar rápida y eficientemente utilizando los instrumentos del derecho.

El hecho de que incluso en una comunidad jurídica tengan lugar violaciones del derecho es, en cierto modo, una trivialidad y no desacredita la idea misma. Los peligros surgirían si el derecho fuese sistemáticamente desatendido o si, con

87 Con más detalle, Baer, 2015 (141 y 142).

88 Hallstein, 1962 (344, 348). 
carácter general, se negara su validez. Dado el gran número de operaciones jurídicas afectadas por la legislación europea, difícilmente puede afirmarse que esto ocurra, a pesar de la existencia de diferentes culturas jurídicas y el manejo laxo de los requisitos legales en determinadas áreas ${ }^{89}$. Además de ello, las alegaciones por violaciones del derecho, tras un examen detallado no están, a menudo, exentas de conflictos en cuanto a la interpretación adecuada de aquellas disposiciones abiertas que necesitan ser desarrolladas ${ }^{90}$. Sin embargo, estos conflictos son, por su parte, un elemento constitutivo de una comunidad jurídica. Aunque los primeros signos de un olvido parcial del derecho no deben ser ignorados. Si persiste la impresión, expresada no sólo en Alemania, de que en conflictos trascendentes el Derecho europeo se reduce a algo elástico o insignificante, no sólo se pone en peligro la comunidad jurídica, sino también la base central de la integración europea.

Voy a finalizar con una cita del decano del Derecho europeo en Alemania, Thomas Oppermann: «Cuanto mayor sea la UE, más necesitará del poder regulador de su ley. La Unión no dispone de fuerza estatal, solo puede conservarse como una comunidad jurídica. El imperio de la ley en el Derecho de la UE es imprescindible para la realización de la idea de Europa. Esto también es aplicable, en particular, a la lucha contra la crisis financiera a partir de $2010{ }^{91}$.

TITLE: «European Integration Through Law» - The Contribution Of The Federal Constitutional Court

ABSTRACT: Many stakeholders are involved in implementing the idea of legal community, including national parliaments, administrations and courts, which for their part are responsible for the implementation of European law. This study addresses the work of the German Federal Constitutional Court in the development of European integration by considering ten central impulses. In addition, to conclude, some realistic reflections on the limitations of the law in the solution of vicissitudes in the framework of the European Union will be provided.

RESUMEN: Muchos actores están involucrados en la implementación de la idea de comunidad jurídica, entre ellos, los parlamentos nacionales, administraciones y tribunales internos que son responsables de la puesta en práctica del Derecho de la Unión Europea. En este estudio se aborda la labor del Tribunal Constitucional Federal Alemán en el desarrollo de la integración europea considerando diez impulsos centrales. Además, para finalizar, se aportarán algunas reflexiones realistas sobre las limitaciones del derecho en la solución de vicisitudes en el marco de la Unión Europea.

KEY wORDS: European Union, German Federal Constitutional Court, European integration, Europe article, juridification.

Palabras Clave: Unión Europea, Tribunal Constitucional Federal Alemán, integración europea, cláusula Europa, legitimación.

FECHA DE RECEPCIÓN: 12.09.2016

FECHA DE ACEPTACIÓN: 01.02.2017

89 Cf. las referencias en la nota 6.

90 La misma visión es sostenida por Volkmann, 2014 (1062).

91 Oppermann, 2016 (para. 19). 
